\section{Charging Systems}

Charging Systems. By Leila H. Kirkwood. (The State of the Library Art, Volume II, Part 3) New Brunswick, N. J.: Graduate School of Library Service, Rutgers, The State University, 1961. 395p. \$8.00.

This book on charging systems, which follows the pattern of previous volumes in the series, "The State of the Library Art", is a "survey of the published and unpublished literature" of the subject. It contains a wealth of material, describing by means of quotations from the literature, procedures to be followed in the charging, discharging, renewing, sending of overdues, etc., as well as the advantages and disadvantages of each of the systems included.

However, this book is not a practical guide for the librarian seeking help for installing a certain system in his library, although this information is there if one can find it. The arrangement of the material-quotations from the literature interwoven by connecting and explanatory sentences - has brought about a certain amount of confusion which makes it impossible to obtain a clear picture of each system described. This, plus a lack of careful proofreading, no sub-headings within the chapters, the absence of a descriptive running title for each chapter ("circulation systems" is used throughout as the running title), and an inadequate index quickly leads one to frustration when using the book.

Speaking of the index, it is fantastic! It does not include entries which one would normally expect to find and which one needs for the proper use of the book. Instead, the index covers much irrelevant material contained not only in the body of the book but in the preface as well. The preface, inci- dentally, is reprinted without change in each volume of the series. Entries for specific subjects, such as costs, periodicals, pamphlets, renewals, overdues, bookmobiles, and the like would have been more helpful, as would the inclusive paging of the various systems described.

The author, in surveying the literature on charging systems, has covered all types of systems, from the earliest times down to and including the present, for public, college, university, and special libraries both in this country and in England. She has included in her bibliography 414 references taken from 698 citations, covering the years 1876 through 1958, a span of over eighty years. These should prove useful to anyone wishing to make a thorough study of the subject.

The chapter on the "Evaluation of Evidence for Statements Made in the Literature" is particularly good, because it includes a few cost and time studies for some of the systems described. This information is hard to find so that it is helpful to have it in one place. In the last chapter of the book, which is on the token system as used in Great Britain, the author concludes with material indicating possible future developments in the field. No mention is made of the ALA Library Technology Project, but presumably the material for the volume was gathered before 1959 when the project was started.

To sum up, this book gives an excellent coverage of the literature on charging systems, as used in all types of libraries in this country and in Great Britain as well. It should prove helpful to the student and the librarian searching for information on the subject. However, an adequate index as well as better arrangement of the material would have made it more usable.-Helen $T$. Geer, H. W. Wilson Co.

In books I find the dead as if they were alive; in books I forsee things to come; in books warlike affairs are set forth; from books come forth the laws of peace. All things are corrupted and decay in time; Saturn ceases not to devour the children that he generates; all the glory of the world would be buried in oblivion, unless God had provided mortals with the remedy of books.-Richard of Bury's Philobiblon (quoted in Philobiblon or The Love of Books, Being a Publication of the Friends of the Colgate University Library. (Hamilton, N. Y.; 1960). [p. 1]) 